\title{
Considering the youth voice: needs and asset assessment in sport for development using photovoice
}

\author{
Tiesha Martin ${ }^{1}$, Carrie LeCrom²,*
}

1 College of Education and Human Development, Radford University, USA

2 Center for Sport Leadership, Virginia Commonwealth University, USA

* Corresponding author: cwlecrom@vcu.edu

\begin{abstract}
With the growth of sport for development (SFD), it is increasingly important to ensure that programmes are intentionally designed to meet the needs of the communities they serve, in a way that helps build community capacity. Still, many programmes have been criticised for not considering the voices of marginalised individuals, specifically youth programme recipients, in the planning and development of SFDprogrammes. Additionally, programmes are developed from a deficit approach where only the needs or negative aspects of the community are being considered in the planning and development of programming. With these issues in mind, the purpose of this study was to assess the usefulness of photovoice as a strategic tool to give youth a voice in SFD needs and asset assessment. Additionally, it examined how practitioners can utilize the outcomes of a needs and asset assessment in planning and implementing SFD programming. The results highlight the assets and challenges that the youth participants identified and the practical use of the assessment from the perspective of programme administrators. The results suggest that photovoice can allow youth programme participants to have a genuine voice in programme development.
\end{abstract}

\section{KEYWORDS}

needs assessment; asset assessment; sport for development; community based participatory research; photovoice

DOI

$10.14712 / 23366052.2021 .9$

\section{INTRODUCTION}

Historically, sport for development (SFD) programmes were created out of the understanding that sport can have an impact beyond physicality, in ways such as building character traits, creating unity, and overcoming bias. SFD can be defined as 'the use of sport to exert a positive influence on public health, the socialization of children, youths and adults, the social inclusion of the disadvantaged, the economic develop-

(c) 2021 The Authors. This is an open-access article distributed under the terms of the Creative Commons Attribution License (http://creativecommons.org/licenses/by/4.0), which permits unrestricted use, distribution, and reproduction in any medium, provided the original author and source are credited. 
ment of regions and states, and on fostering intercultural exchange and conflict resolution' (Lyras \& Welty Peachey, 2011, p. 311). SFD programmes have emerged across every continent, utilising a multitude of sports, and addressing numerous social issues including disability, education, gender, health, livelihoods, peace, social cohesion, and infrastructure, among others (Svensson \& Woods, 2017). However, within these programmes exist issues of power and equity, as many initiatives are led by those in high socioeconomic societies intending to assist lower socioeconomic communities, which has caused many issues (Darnell, 2012; Levermore \& Beacom, 2012; Spaaij et al., 2018).

Within SFD literature, scholars have argued that the voices of participants should be a more central focus of programme development (Collison \& Marchesseault, 2018; Darnell, 2007; Giles \& Lynch, 2012; Hayhurst, 2009; Kidd, 2008). Additionally, there is a need for better mechanisms to monitor and evaluate programming (Coalter, 2007), and to include local participants in the planning and development stages of SFD (Edwards, 2015; LeCrom \& Dwyer, 2015; Nicholls et al., 2011; Schulenkorf, 2012; Spaaij et al., 2018). Given this, the use of community-based participatory research (CBPR) has grown within the field. CBPR is a method that purposefully incorporates participants from historically disenfranchised groups within society (Green \& Haines, 2015). In addition to a lack of participant involvement, many scholars have noted that SFD interventions tend to be designed from a deficit approach (Giles \& Lynch, 2012) that focuses on only the negatives and none of the progress or positives (Wright \& Lopez, 2002).

With these challenges in mind, the purpose of this study was to examine how photovoice can be used as a strategy to include the youth voice in SFD planning and programming. This is critical in that the youth voice has often been absent from programme development; in addition, the approach utilised here provides opportunities for the community to be assessed in terms of both its strengths and challenges, not just its deficits. In order to tackle this purpose, the research team partnered with a community centre that was looking to revamp their sport programming to include more deliberate SFD. The community centre was concerned with including their youth participants in this process, and in doing so needed an assessment of how the youth viewed their community. The following research questions were used to guide the study:

1) What do youth community centre members view as assets and challenges of their community?

2) How can the results of the needs and asset assessment guide future SFD programming for the community centre?

\section{Literature review}

\section{Needs assessment in SFD}

SFD scholars have called for stronger participant voices in program development (Darnell, 2007; Giles \& Lynch, 2012; Hayhurst, 2009; Kidd, 2008). Based on a review of SFD policy documents, Hayhurst (2009) found that SFD policies and programs tend to be driven by politics rather than by the needs of individuals or groups that are targeted. The author also suggested that in many instances, "first-world" values and 
beliefs are placed on marginalised groups in the development of SFD programmes and policies. Instead, Hayhurst (2009) proposed that policy makers and program administrators should consider the values, beliefs, and experiences of those marginalised groups in developing SFD programing and policies.

In addition to a lack of community involvement, there have been other criticisms about how some programmes are conceptualised and developed. Specifically, many scholars have noted that SFD interventions tend to be designed from a deficit approach (Giles \& Lynch, 2012). That is, programme developers have focused on identifying problems that exist in communities and design programmes that aim to address those negative issues. Scholars have disapproved of these programmes because they tend to reinforce a negative bias of marginalised populations and their situations (Wright \& Lopez, 2002). Researchers have suggested a need to consider the various characteristics of communities, and create programmes that go beyond the identification of problems or treatment of symptoms, but instead focuses on a more holistic based solution model (Cox, 2006; Giles \& Lynch, 2012). This requires that input from all constituencies be considered throughout the process.

\section{Community-based participatory research in SFD}

Community-based participatory research (CBPR) has grown within the field in response to those feeling the participant voice has been left out of programme planning. CBPR strategically incorporates participants from historically disenfranchised groups within society (Green \& Haines, 2015). Researchers have used these methods to engage those living in poverty, ethnic and racial minorities, women, and children (Dubnewick et al., 2018; Hayhurst et al., 2016; McHugh et al., 2015). For example, McHugh and colleagues (2015) utilised one-on-one interviews, sharing circles, and photovoice to understand the experiences of Indigenous Canadian youth so that sport programming could be better tailored toward that population, while Hayhurst and colleagues utilised the same methods (interviews, photovoice, sharing circles) in examining SDG programmes targeting Aboriginal young women in Vancouver (Hayhurst et al., 2015). Furthermore, in an effort to better understand the sport experiences of youth, researchers applied CBPR in the form of one-on-one interviews and focus groups with community youth and adults (Dubnewick et al., 2018). Much of the CBPR within SFD utilizes methods such as focus groups and one-on-one interviews (Dubnewick et al., 2018; Hayhurst et al., 2016; McHugh et al., 2015). Similarly, Collison \& Marchesseault (2018) introduced the concept of participation social interaction research (PSIR) into the field of SFD, noting the ways it gives voice to culturally specific contexts. The authors applied the approach across developing countries in Africa and specifically identified the way it "empowers local voices to construct detailed accounts of culture within and outside of SDP" (Collison \& Marchesseault, 2018, p. 226). Hayhurst (2017) advocates for participatory methods, specifically those more visual in nature (photography, video, blogs, zines), in that they have the power to build trust and collaboration through the process.

\section{Power and voice}

One of the main issues CBPR, PSIR, and other participatory research methods aim to amend is the lack of voice and power among marginalised groups, often the groups 
from whom data is being collected and for whom programmes are being planned. Power, voice, and empowerment are complex phenomenon, influenced by centuries of cultural, economic, and political oppression. Jo Rowlands, specifically addressing internalised oppression of the female gender notes, "a group of people who are systematically denied power and influence in the dominant society will internalize the message it received about its supposed roles and capacities and will come to believe the messages to be true" $(1998$, p. 12). It is likely that youth face a form of internalised oppression, as they can be seen and treated by many adults as vulnerable, incompetent and immature (Grace, 1995), therefore minimising the power of their voice. However, steps can be taken to shift this view over time.

A good example of this would be student voice. Over the last several decades, educators around the globe have slowly begun to recognize the value of student voice as a contributor to the education system in general (Bahou, 2011). Students are being asked for feedback and ideas that can contribute to how education is delivered and received. They are being viewed as 'expert witnesses' (Flutter \& Rudduck, 2004, p. 4) and are a voice in shaping their own education. While there are certainly challenges to this approach, where implemented properly, the results are predominantly positive (offers teachers important insights into learning, better engagement between teachers/learners, more motivated students, less absenteeism, etc.) (Bahou, 2011). However, for student voice to truly make an impact, there must be a strong commitment on the part of the administration to listen to and respect the views of the students (Bahou, 2011). The overall respect being offered to youth in student voice movement demonstrates Rowlands' statement that the more power is exercised, the more it can grow (1998).

In general, power and voice continue to be challenging concepts when applied to any marginalised group, a group within which youth certainly fit. Voice does not guarantee power. "Voice means having a say when asked but without any guarantee of a necessary response" (Bahou, 2011, p. 3). There need to be people in positions of power who are willing to listen and defer in order for voice to become power. The current study offered a unique opportunity to explore some of these dynamics, in that SFD programme administrators specifically appealed to the researchers to help guide them through a process fully focused on the youth voice and how it could guide future endeavors.

\section{Needs assessment and asset/capacity building hybrid model}

The current study utilised the needs assessment and asset/capacity building hybrid model proposed by Altschuld, Hung, \& Lee (2014) as a theoretical guide. Until rather recently, community development practitioners and scholars have planned for the improvement or development of social programming from a needs-only approach, taking into account only what is needed, wrong, or missing within the community (Altschuld et al., 2014; Green \& Haines, 2015). Traditional needs assessments are commonly led by external parties, and are initiated in response to problems either within the community or within organisations that conduct programming in the communities (Costa \& Serrano-Garcia, 1983). Despite the past focus on a needs-based approach, there has been a shift, and scholars and practitioners are beginning to stress the importance of considering assets, strengths, and resources that exist within the community 
that might assist in programme development (Green \& Haines, 2015; Kretzmann \& McKnight, 1993). Researchers have indicated that focusing on assets may help mobilise communities to address their issues and help build community capacity.

Altschuld and colleagues (2014) proposed a hybrid model in which needs assessment and asset building are not viewed as separate and opposite; rather, they are used in conjunction to support each other in the community development process. Through this integrated model, programme recipients should not only provide the data, but should also be actively involved in the process of developing or changing programming (Altschuld et al., 2014). Figure 1 provides a visual depiction of the model.

\section{Synthesis}

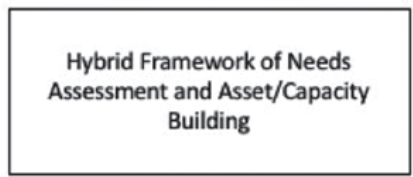

Thesis

Needs Assessment

Conflict

Figure 1 Hybrid framework of needs assessment and asset capacity building

Altschuld, Hung, \& Lee (2014) suggest that a hybrid approach should determine needs and assets independently, yet in a way where both are connected. The asset assessment should focus on building community capacity for change by allowing individuals to consider the assets or strengths of a community or organisation (Altschuld et al., 2014). The needs assessment component should work to determine the gap between 'what should be' and 'what is' by focusing on what the community or organisation needs, discrepancies, or shortcoming that may exist. Authors have noted that assessing the needs and assets simultaneously can prove useful in building community capacity and for deciding how best to use the assets to address the needs (Belvins, 2017; Curtis, 2018; Platt, 2016).

\section{METHODS}

The current study utilised a multi-method qualitative case study design to understand how youth members of a community centre view needs and assets in their community and how those needs and assets can be used by centre administrators to develop SFD 
programming. This design was chosen because qualitative research is necessary to uncover the complex issues that inform SFD programmes (Steward-Withers \& Brook, 2009), in that the design can elicit thick description of the experiences of the community participants (Van Manen et al., 2015). Thus, this needs and assets assessment was performed using a photovoice project with SFD programme recipients (youth members), and interviews with programme administrators.

\section{Research setting}

A community centre located in a low-socioeconomic urban neighbourhood on the East Coast of the United States was used as the setting of this case study. The community centre is in one of the lowest income neighbourhoods in America with an average household income lower than $94.5 \%$ of neighbourhoods in the United States (NCCP, 2016). Furthermore, with $74.7 \%$ of the children living below the federal poverty line, this neighbourhood has a higher rate of childhood poverty than $98.7 \%$ of U.S. neighbourhoods (NCCP, 2016). Additionally, the crime rate in the area is about $25 \%$ higher than the national average (Zimmerman et al., 2016). The community centre is committed to improving the lives and meeting the needs of youth living in the community, and currently serves approximately 300 youth in their after school and summer programs. This centre was chosen because administrators were interested in assessing the needs of the community they serve, and determining how they can better meet the needs of their youth members through their sport programming.

\section{Participants}

From within the chosen community centre, a total of 11 individuals participated in this assessment. Youth participants and adult administrators were recruited based upon their involvement in the afterschool sport programming offered at the centre. To recruit the youth, a member of the research team attended the Fall open house, which is held at the centre annually, where local youth and adults come to find out about fall programming offered. At this open house, the needs assessment and capacity building project was presented, and parents whose youth were interested signed up that night. Eight youth, ranging in age from 10-14, signed up. There were a total of 3 boys and 5 girls that participated in the photovoice project.

Additionally, three community centre administrators were purposefully selected to take part in this assessment. Administrators were selected based on their role within the centre, and their ability to provide relevant and useful information related to the needs and assets of the community (Onwuegbuzie \& Collins, 2007). One of the administrators is a member of the board of directors, another is the executive director of the centre, and the final administrator is in charge of the centre's sport programming. Two of the administrators lived in the community at some point. To protect participants, pseudonyms were assigned in the presentation of results.

\section{Data collection}

Photovoice. In the current study, a photovoice strategy was utilised to include the youth voice in the SFD planning process at a community centre. It was coupled with focus groups to enrich the researchers' and centre administrators' understanding of how the youth viewed the needs and assets within the community that could lead to 
the most appropriate and effective SFD programming at the centre. Photovoice, based on its creative and non-verbal format, has been identified as a strong data collection tool for youth (Hudson et al., 2020).

Data collection for the photovoice project lasted approximately 11 weeks, closely following the procedure laid out by Wang \& Burris (1997). Cameras for this project were purchased with internal grant funds from the researchers' institution. Prior to the start of the project, participants were trained on how to use the cameras, as well as safety and ethical issues related to photography. Next, participants engaged in four group photography sessions, where all participants, along with a researcher, went around the community together for approximately one hour. Youth participants were responsible for selecting the sites they wished to visit. During these photography sessions, the youth were only instructed to take pictures of things that represented their experience living in the community. They were not asked to specifically identify needs and assets. The youth additionally took the cameras home for one week to take photographs of the community assets and needs on their own. Group and individual photography sessions yielded a total of 325 pictures.

In addition to the photography sessions, youth participants engaged in four focus group discussion sessions, where they came together to discuss the photographs they took, specifically discussing what their photograph was and what the photograph said about their community (i.e., if the picture represented a positive component (asset), or a shortcoming (need)). A research team member guided these group discussions. Group discussions were audio-recorded, then transcribed verbatim. Both the photographs themselves, as well as the group discussion related to each, were collected as data.

During the final group discussion, participants were tasked with selecting 20 pictures that helped tell the story about their community and their experiences living in the community. The 20 pictures that were selected were printed and framed. As a group, the youth prepared a presentation in which the 20 pictures were showcased and accompanied by explanations. The presentation was attended by community centre administrators, staff, youth members, families of participants, and other members of the community.

Interviews. Interviews were used for the current study to elicit reflection on the needs and assets identified by the youth and about how those needs and assets could inform future SFD programming. Following the conclusion of the photovoice project, one-on-one, semi-structured interviews were conducted with each centre administrator. The interview protocol (Appendix A) included questions about the general perception of the community, and how the results of the photovoice project can inform SFD programming moving forward. The interviews were conducted by a member of the research team and lasted between 35-50 minutes. Each interview was audio recorded and transcribed verbatim.

\section{Data analysis}

Miles \& Huberman (1994) and Patton (2002) suggest a deductive approach to data analysis, using theory to guide discovery. In analysing our data, we followed a systematic deductive approach, where we began with a premise based on the needs assessment and asset/capacity building hybrid model, and made sense of the data from this 
frame. In doing this, data were coded into categories that fell under assets and needs, with different trends emerging within each. This prefigured coding scheme allowed additional codes to emerge into broader themes.

Atlas.ti software was used to store data and assist in data analysis. Researchers paid close attention to trustworthiness throughout the data collection and analysis process (Lindloff \& Taylor, 2011). To reduce individual bias, two researchers were involved in the coding of data. One of these researchers was involved in data collection and the other was not. Each researcher individually openly coded the data, in a process where each was immersed in the data, looking at all photographs, and re-reading all transcripts from the focus groups and interviews (Lenneis et al., 2020). This resulted in various codes, at which point each researcher again went through the codes, trying to generate initial themes. As a third step, the two came together to collaborate on establishing final trends and themes discovered through the data. Inter-coder reliability was established only if both researchers identified a theme in the initial coding process, at which point it was moved forward for further discussion (Creswell \& Poth, 2017). Discussion around themes took place over a number of sessions, in between which researchers would go back into the data to ensure they were respecting the words of participants. Finally, the reduction process resulted in two overarching themes and six subthemes when it came to assets and needs. Additionally, a final theme related to the practical value of the needs and asset assessment is discussed.

\section{Researcher stance}

It is important, especially in qualitative work, to understand the standpoint from which a researcher approaches his or her work (Maxwell, 2013). Both researchers involved in this project have spent time working with youth and community centers in the neighborhood where the project took place. Through their work, they have an understanding of the demographics within this community and the issues youth in this area face daily. While they do not reside in this community, their work there has given them an outsider's perspective on the youth with whom they would be working. Because of this, they were able to work to establish trust and communicate the purpose of the study clearly so that participants could be open and honest in their participation.

Given their own backgrounds, great care was taken in approaching this work in an unbiased manner. During the photovoice sessions, focus groups and interviews, the researchers asked questions in a straightforward manner without inserting their opinions or thoughts into the conversation. The participants led the conversations in the direction they saw fit, with the researchers guiding the discussion purely from a standpoint of keeping it focused on community assets and needs. The researchers also looked for any cases where their own views appeared in any of the transcripts of the focus groups or interviews, to ensure they remained as unbiased as possible. Through these deliberate strategies, the scholars are confident that they have respected the voices of those in the community, rather than inserting their own views into the findings.

\section{RESULTS}

The aim of this study was to examine how photovoice can be used as a strategy to include the youth voice in SFD planning and programming. The results revealed that 
youth saw multiple assets within their community, such as 1) their community being close-knit, 2) multiple community resources, 3) education, and 4) positive outlets. On the other hand, youth identified 1) violence and 2) subpar community facilities as needs or challenges in the community. In addition, in order to examine the practical value of the needs and asset assessment, interviews with programme administrators were conducted. The results revealed that programme administrators valued the photovoice project in its ability to give voice to the youth who are often overlooked in these types of processes, and they planned to use the information provided by the youth to inform future SFD programming. Additionally, administrators saw value in giving youth a voice in decision making within the programme overall. Each of these aspects are discussed in detail in the following section.

\section{Community assets}

The youth who participated in the photovoice project commonly identified several key assets within the community in which they live. The most salient asset was the idea of Close-Knit Community. Youth participants stated that the community is close in the sense that people know, trust, and care about each other. During one of the photo sessions, Nia, age 10 took a picture of her grandmother's church. She later explained, 'They [members of the church] are nice. They ask me questions about my life and myself. I got baptized there. They support me because I think they care.'

Participants also described the Close-Knit Community as one where community members look out for each other. Camryn, age 13, talked about the Close-Knit Community as she discussed a picture that she took of a street in her neighbourhood. She explained:

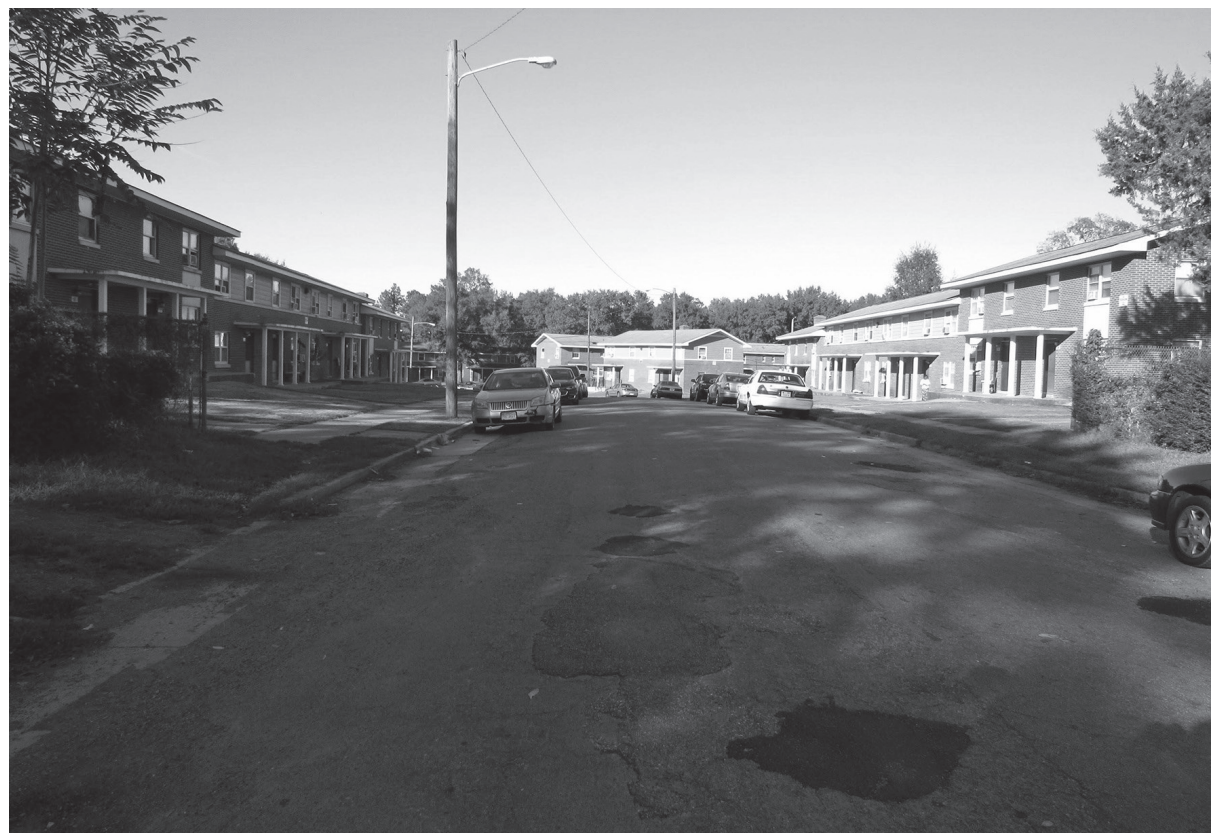

Figure 2 Neighbourhood 


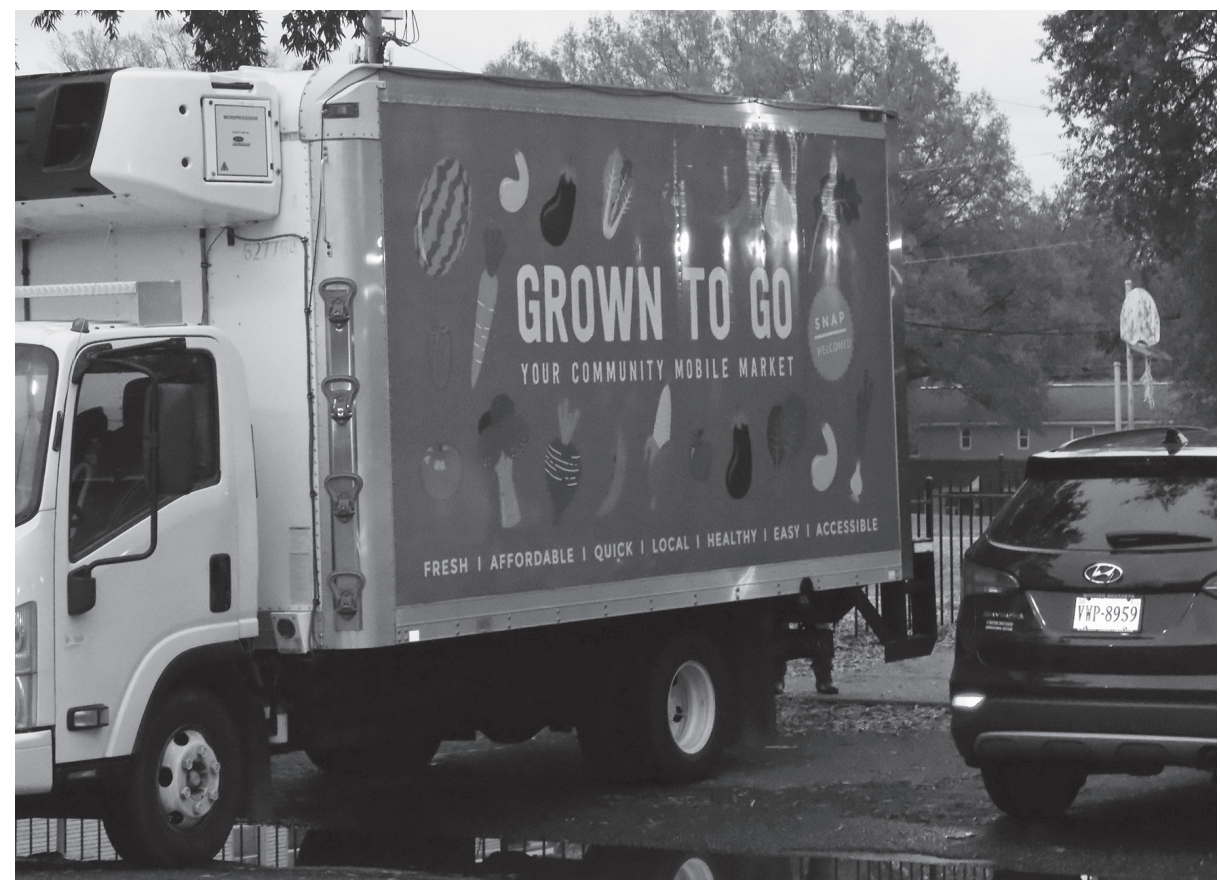

Figure 3 Community resource

This street it's just exciting to me, because when you need something from your neighbours, they'll be right there. Like if your parents aren't there and you told them that they weren't there and the door was unlocked, they'll make sure that you're in there. They'll check on you and stuff. That's the one thing I love about that street.

Nicole, age 12, echoed this point during discussion. She expressed, 'I guess the people are nice. My next door neighbour, she’s old. She watches me sometimes, like when my mom is at work or when the club is not open.' As evidenced by the youth, the Close-Knit Community is clearly an asset.

Another asset of the community identified by youth was Community Resources. Youth pointed out that not only are there external resources being brought in to the community by non-profit organisations, there are also resources, such as facilities, that are a part of the community's built environment. For instance, during discussion, Carlos, age 13, shared, 'I like the park by my house. I like to go there because I can play basketball and they have a field and sometimes we play kick ball. It's just a place to go to hang out with my friends.' Shawn, age 11, talked about another Community Resource as he discussed a picture that he took during one of the sessions:

I took that picture because it's a recreation centre right there and [a non-profit organisation] bring food for free to there, and I think that's good for kids to have food and a recreation centre. Because if kids, like homeless kids, they don't have food, they can go to the recreation centre. You play basketball or you can drum, and once the food comes, you can eat for free. 


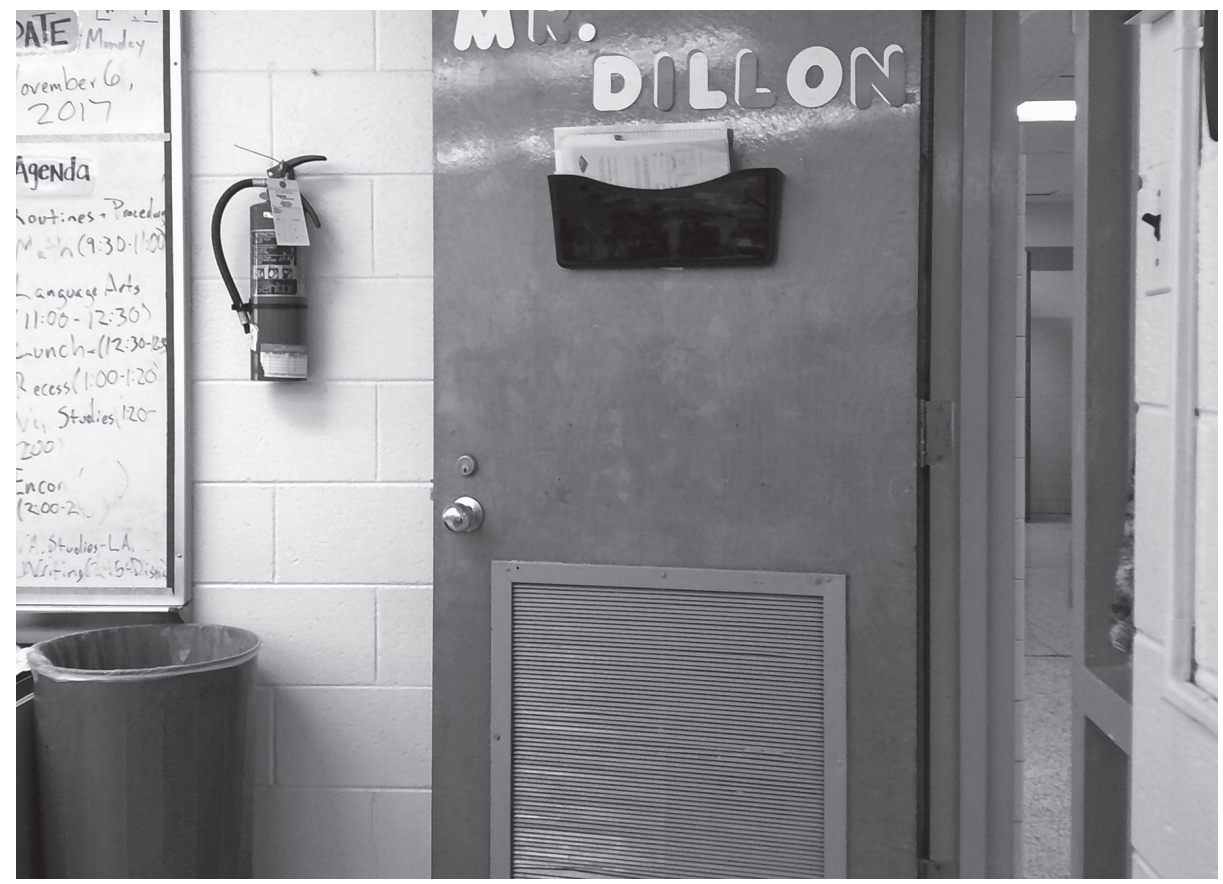

Figure 4 Classroom

Clearly, youth viewed Community Resources as a positive aspect of the community. Third, youth participants identified Education as an asset. The youth shared how important education was to their future. Andrea, age 14 shared, in response to a photo taken of a classroom:

School to me means a future, because you can't be nothing without school. Like if I dropped out of school right now, I'm not going to get nothing at all. When I'm old enough to get a job, I'm probably going to be working at Chick-fil-a, Popeyes, and McDonalds for the rest of my life.

Additionally, Tina, age 12, shared, 'But why do all those people have guns and have to sell drugs and stuff? My mama said that if go to school, get good grades, go to college, I won't have to sell drugs.'

Finally, the youth participants talked about Positive Outlets as avenues such as music, sports, church, and friends, that help them escape some of the negative aspects of life. Camryn, age 13, took a picture of her music class and shared with the group, 'I took it because it helps relieve my stress about school, personal life, friends and family...I put all of my feelings into music.'

Nia, age 10, also shared how church is a Positive Outlet for her. She stated, 'I love church. Because I praise the Lord. Because the stuff that's happened in my life, I can pray. My aunt is an alcoholic, and I try to pray to the lord so that she can stop.' Other photos taken and discussed by the youth related to Positive Outlets, including the sports offered by the recreation centre. 
In summary, the youth participants acknowledged their community was close, the community had multiple resources, there is an opportunity for education, and there are positive outlets for youth in the community. These were all deemed as community assets.

\section{Community challenges}

In terms of community needs, youth participants discussed many challenges that exist in their community. By far the biggest challenge was Violence. Participants described the community as unsafe and filled with gang related activity and shootings. During a photography session, one participant took a picture of graffiti at a park. This started a discussion about gang activity in the community. Shawn, age 11, shared with the group, 'It's a crazy world out there. People shooting people. Makes me feel not safe. My granddad carries a gun just in case.'

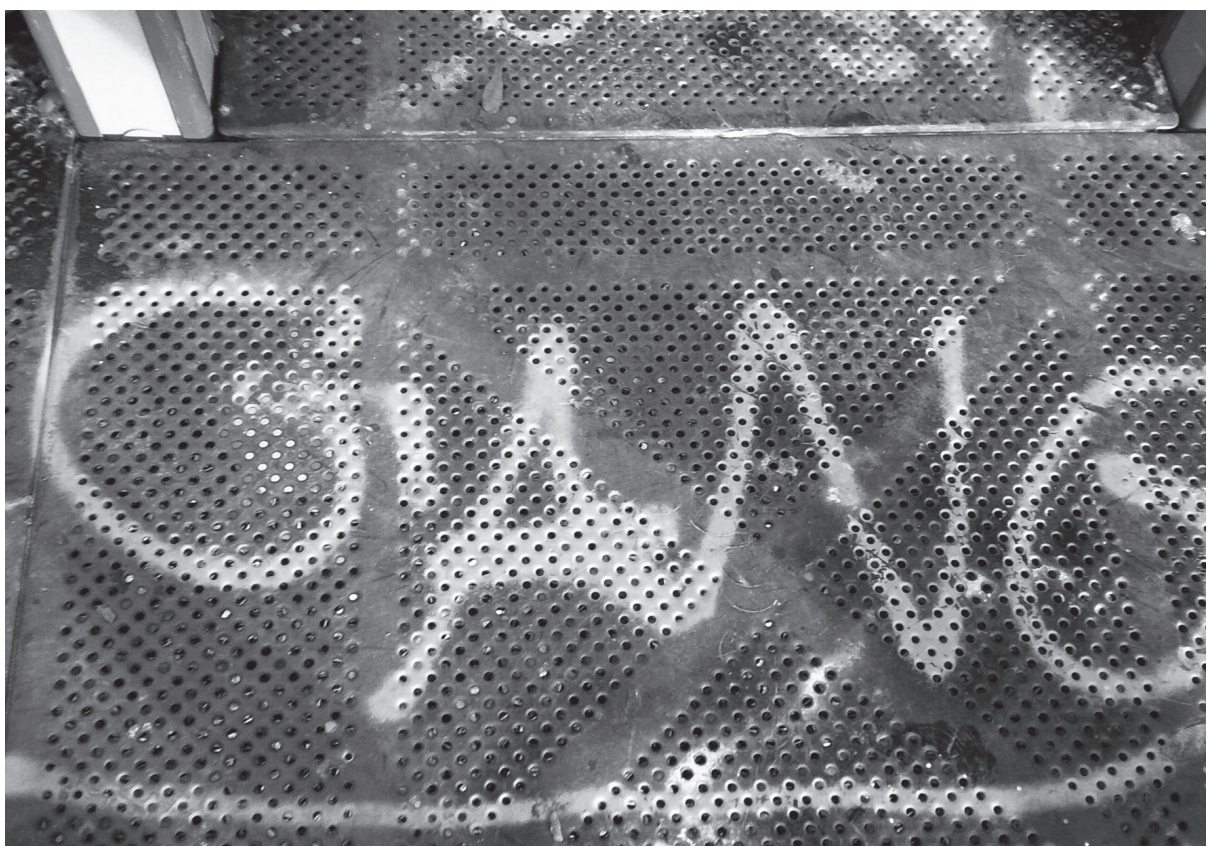

Figure 5 Park graffiti

Others echoed his sentiment of not being safe. Nicole, age 12, shared her experience, stating:

I have to be honest. People be doing bad stuff. Shooting and selling drugs. My friend's brother used to sell drugs but then he got shot. He died. He was like 16 or whatever. People do other bad stuff too. My mama don't like me walking around at night because she think I might get robbed or something.

Also in regard to Violence, participants shared their fear of being a victim, especially at a young age. In response to a picture taken at a local cemetery, the group discussed 


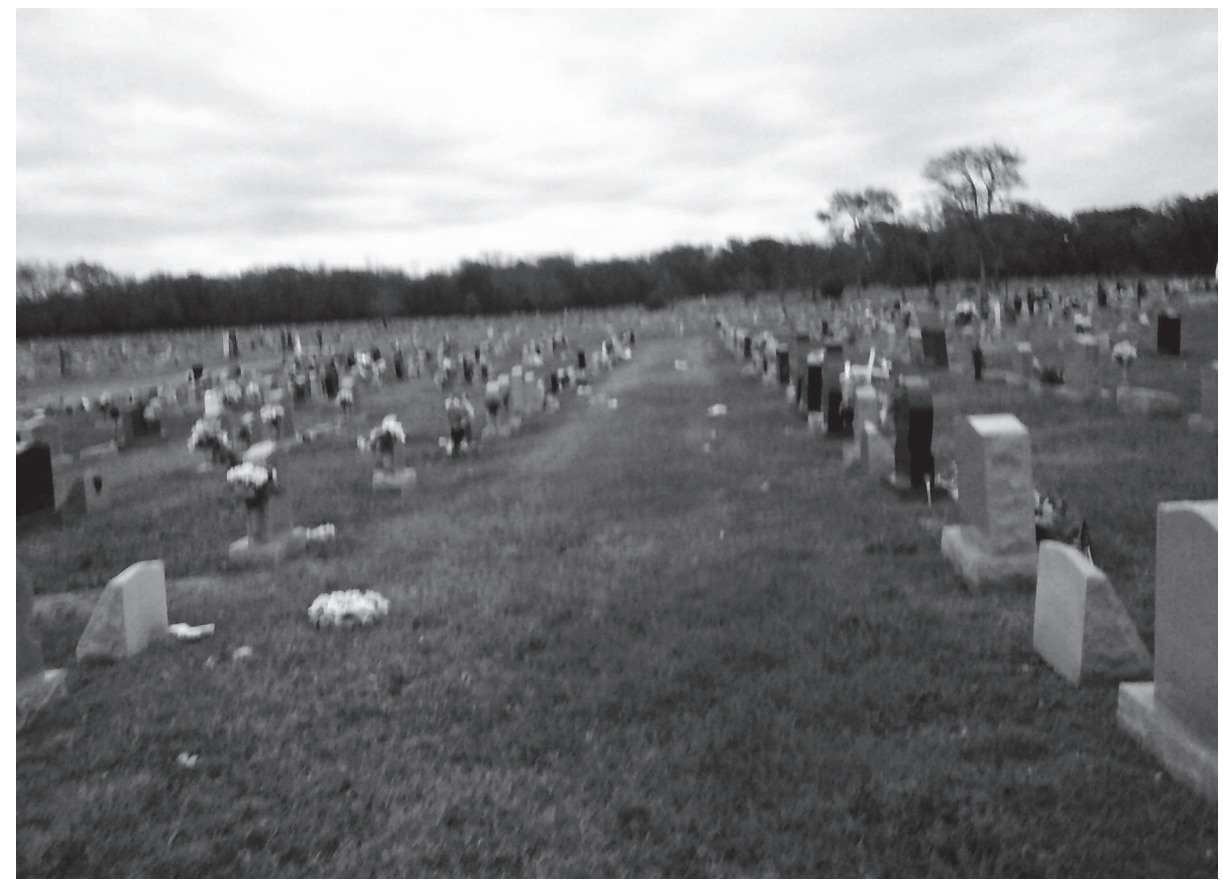

Figure 6 Cemetery

the likelihood of dying young. Andrea, age 14 shared: 'It's sad, but people get killed every day. It doesn't matter how young. You could just be in the wrong place at the wrong time.'

Additionally, when asked about how Violence made her feel, Carlos, age 13, responded, 'Sad. And I don't know ... scared. I mind my own business, but I could still get shot. You never know.' Clearly, as indicated by the youth, Violence is a challenge for this community.

In addition to violence, Community Facilities was another salient challenge or need of the community. Youth noted that while there are some recreational facilities that they can utilise in their community, there are not many and the quality of the facilities is subpar. Tina, age 12, stated during discussion:

I play sometimes at [a park], but sometimes I don't like to go there because it's dirty. The net thing is all raggedy and the there's trash all over the court and stuff. And there's always people standing around on the court. Not even playing but just stand there.

The issues with Community Facilities came up among others as well. Marcus, age 10, who took a picture of the equipment when the group visited a local park, explained:

I took this picture because the city needs to come, and kids need to stop jumping up there and tearing...when they jump up on the net and they hold on to it and try to get up to the rim, they stretching the net. And the city needs to fix that and get all that glass up and fix them courts because the courts are rusty, dusty, dirty and trifflin. 


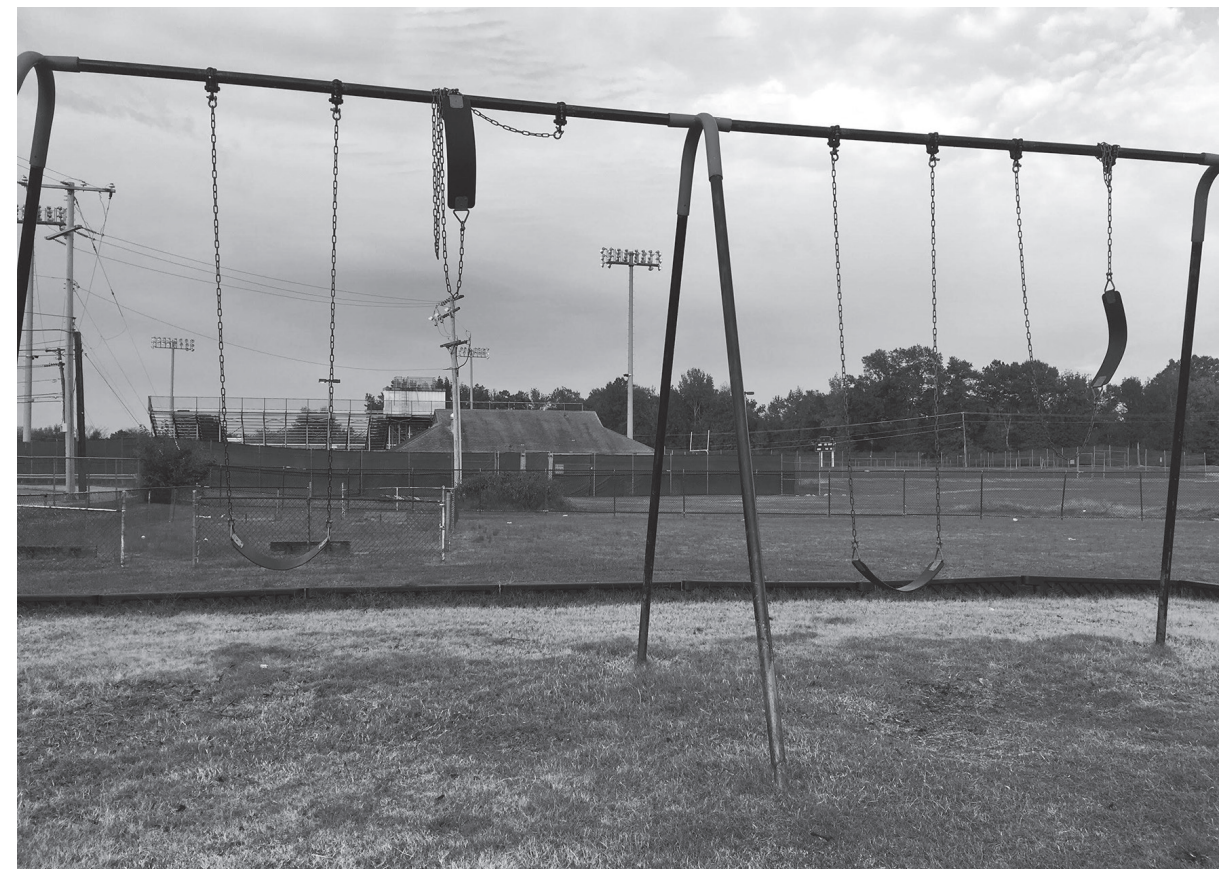

Figure 7 Playground

Collectively, there are many needs in the community identified by the youth, but many of them come back to violence, gangs, and the damage that is being done by those affiliated with these things.

\section{Practical use of youth-identified needs/asset assessment}

Research question two dealt with how results of the youth-centred needs and asset assessment could be used to influence SFD programming for the centre. Administrators saw a chance to use the results of the needs/asset assessment to improve upon their sport programming. Specifically, administrators discussed how to use the identified assets to improve sport and programming, as well as how sport could specifically address the identified challenges. The administrators were collectively impressed with how much information was gleaned from the youth through the photovoice project, and the youth input encouraged them to think differently about their sport programming.

Concerning the use of assets to improve programming, the administrators focused primarily on utilising the asset of Community Resources. According to Mr. Paul, the sport programme director, 'We should be partnering with organisations that are in the community. We do already, but we should continue to do that. Partner with the churches, the schools, to recruit.' Mr. Griffin, the executive director, added:

Maybe working with the other parks and things in the neighbourhood, getting those cleaned up so that we can use them, and so that other kids in the community can use them. Even if they don't attend our [centre]. 
Next, Mr. Griffin spoke to how the centre can use sport to address some of the challenges that were identified through the needs/asset assessments. He explained:

We talked about maybe incorporating some of our other programmes like Positive Actions or Passport to Manhood with sport. And based on what the kids pointed out, Positive Actions would be good for them. It's evidence-based that it helps reduce violent behaviour among kids. Since violence is an issue in this community, then I think we could do that.

In addition, administrators acknowledged the youth perspective in that the youth saw Education as an asset, while the administrators would not have identified it as such. In reflecting on this, Mr. Crawford, the board member, talked about using sport as a hook to get kids involved in the education programmes the community centre already offers. He said, 'using sport and having a sport presence can get kids involved and we can reach them through the other programmes that the [centre] offers. The education programmes, and the other ones.'

Finally, administrators talked about the importance of giving youth participants a say in the planning of the programme moving forward. They spoke to how the photovoice process was a good way to involve youth and give them a chance to share their experiences. Mr. Paul shared: 'I think that's part of why this project was so interesting. It's good to give kids a voice and a chance to share their reality.' He further explains:

I think one of the things that I perceive that we don't do enough of is really ... I'll just call it the youth voice. I think as kids grow older, they'll want more input and they should. And I think that we can do more to develop that youth voice. Both in terms of programmes and content that is meaningful to them. I think that's important for developing good programmes, I think it's important for developing self-confidence.

The other administrators agreed with the importance of giving youth a voice. Mr. Griffin concurred:

We can't, or shouldn't tell these kids what they need. They have to tell us. We can't assume that we know. This photo project ... it gave them the opportunity to tell us what they need. What is important to them.

Seemingly, programme administrators saw the benefits of the youth-based needs/ asset assessment, in that it gave youth a chance to be involved in the decision making and direction of the community centre.

\section{DISCUSSION}

The purpose of the current study was to encourage a more thoughtful inclusion of the youth voice in programme development and reconstruction by examining how administrators of a community centre can utilise the outcomes of a youth-focused needs and asset assessment in sport programme planning and implementation. This study was conceptualised out of the concern for the lack of youth voices involved in the programme development process (Green \& Haines, 2015; Hayhurst, 2009), and 
the challenge of finding a way to pull deep, rich information from a youth population. The results of the study shed light on what youth participants saw as assets and challenges within the community in which they live. In addition, the results highlight how the administrators who are involved in SFD programming plan to utilise the information provided by youth participants.

Research question one was concerned with determining what youth programme participants view as assets and challenges in the community in which they live. Utilising a photovoice project allowed for information to come forward in various ways. The photovoice strategy seemed to elicit rich, descriptive information from the youth, in that it took them out into their community where they could see and document assets and needs in real-time. Youth took pictures of things that they viewed as positive aspects of their community, as well as things they viewed as challenges, then the researcher led them through discussions around these topics.

Research has suggested that being a part of a photovoice project can give youth an opportunity to think about their community in a way that they had not or could not before (Leung et al., 2017; Strack, Magill, \& McDonagh, 2004). The depth and breadth at which the youth were able to discuss the assets and challenges in their community was strong within the photovoice project. Given that photovoice participants had pictures to facilitate the discussion, they were able to talk about the assets and challenges they identified in great detail. This study provides evidence that giving the youth a different, perhaps more creative way to express the assets and needs of their community (photovoice), led to detailed and expressive responses that are very useful to the administrators at the centre. This is consistent with Wang and Burris' original hope of photovoice - that it would 'promote a process of participation that would be analytical, proactive, and empowering' (1994, p. 179). In addition, Hayhurst (2017), in reflecting on two experiences using visual data collection methods such as photovoice, notes that "SDP participants are potentially able to better exert agency and strategically heighten their own voices to key decision-makers" (p. 119). She adds, however, that this is not a solution to unequal power relations or a host of other challenges of SFD, but that it is a method that may be worth further examining in its ability to build collaborations.

Overall, the photovoice initiative resulted in important data from a group often left out of the conversation (youth). In a systematic review of SFD in South Africa, Laureus identified improved youth participation in SFD as a recommendation and remaining need (Laureus, 2019). Similar to Laureus's findings, there is a likelihood that the youth participants in this study have not been asked their input or opinions on community issues in the past. Therefore, by simply being participants and leaders for change, feelings of empowerment may have begun to emerge. As with issues of voice and power among marginalised groups, there is often the slow change that takes place over time. Rowlands discusses these small changes over time among women moving through an empowerment process (things like perceiving themselves as capable, initiating activities, etc.), noting that 'they do not in themselves, however, demonstrate empowerment processes: they demonstrate the product of empowerment processes the evidence that empowerment has been taking place' (1998, p. 23). It is the hope that the process the youth participated in here helped them view themselves as important players in their community. This is a sentiment expressed by the programme administrators as a potential outcome of the project. 
The longer-term impact on the youth themselves, however, is also contingent upon how the data they provided will be used moving forward. If the youth are unable to see change as a direct result of their input, then it is likely that they will continue to operate from a standpoint of internalised oppression. As stated previously, youth do have a voice, but the question is who is giving power to that voice and in what ways, leading into research question two.

The results pertaining to research question two suggest that programme administrators saw the value of the youth-led needs and asset assessment, and they planned to use the information that the youth provided to enhance the centre's sport programming. This finding is consistent with the overall goal of photovoice and other forms of needs and asset assessment, which is to reach programme administrators or policy makers and allow for critical discussion (Hayhurst, 2017; Wang \& Burris, 1997; Wang \& Pies, 2004; Wang et al., 2004). Additionally, needs and asset assessments should help build community capacity by helping programme coordinators determine how to best use the assets in the community to address the needs (Curtis, 2018). This was clearly the case with programme administrators in this study, as they recognised Community Resources and Tight-Knit Community were both assets that could be used to address some of the issues with Violence, and to improve upon the centre's SFD programming. When asked to consider the information that the youth provided, centre administrators cited some of the pictures that the youth took and how this enhanced their understanding of how the youth view their community. In Hayhurst's work (2017) she found that photovoice helped others better understand a wider range of viewpoints related to SFD, which the administrators seemed to also feel through this project. This further highlights photovoice as an effective needs and asset assessment tool to help guide SFD programming, and speaks to the importance of including youth in the process when programming is being created for them. This could, more broadly, be applied in cases where curriculum is being designed or redesigned. For instance, the Czech physical education curriculum has been criticised as 'not working,' and Petr Vlček (2020) suggested a framework for assessing and improving it, yet it seems only adults are involved in the solution; more thoughtfully including the youth voice in this process could result in findings not uncovered when only involving teachers and administrators in the process.

Finally, empowerment is an essential part of photovoice and other needs and assets assessment techniques, where participants should feel inspired and enabled to effect change in their community (Strack et al., 2004; Wang et al., 2004). While it seems empowerment may have been fostered through the photovoice project by giving youth a chance to share aspects of the community and elements of their lived experience, the impact should be approached cautiously. In critiquing photovoice as a technique, Liebenberg points out many topics for consideration. She notes that, 'concerns add weight to the current critiques of photovoice, underscoring the importance of meaningful collaboration, rigorous research, and skillful sharing of findings in establishing true participant empowerment and meaningful social change' (2018, p. 7). In short, the needs and asset assessment in itself is not what is empowering; it is the short- and long-term changes that result from a project such as this that can result in empowerment among the youth. This is heavily influenced by the programme administrators involved. 
Administrators in this study emphasised the importance of giving youth a say in the programming that is directed toward them. This youth voice is essential as more often than not, programme administrators are outsiders to the community and youth community members may offer a different, more nuanced perspective to some issues (Leung et al., 2017). Within SFD needs and asset assessment and programme development, the youth voice has historically been ignored and the perspective of administrators and funders are given preference (Green \& Haines, 2015). This case study hopefully sheds light on how youth can be a part of a needs and asset assessment geared toward improving SFD programming in their communities. However, there must be buy in from program administrators in order for this to have an impact, so more work stands to be done on how we can create the environment that values multiple voices in the process.

\section{Limitations}

In addition to some of the limitations that exist in nearly any qualitative study or case study (sample size, bias, generalisability), one other potentially impactful limitation was identified. Because programme administrators were aware of the purpose of the study before interviews were conducted, reactivity may have occurred. According to Maxwell (2013), interviewees are often reacting to the interviewer rather than the situation being observed; participants may mislead in an effort to give researchers the answers they think they want. Thus, administrators may have overstated their desire to use the needs and asset assessment in their future planning of centre activities. Maxwell (2013) makes it clear that one cannot fully eliminate the threat of reactivity, thus it is a limitation of this study. Following up with administrators and continued collaboration with the centre will be the only way to truly know the impact of this project. In addition, this study was conducted in the United States, so its generalisability beyond North America is unknown. Given that many SFD programmes operate in the Global South, more work would need to be done to assess its applicability in different geographical settings. Finally, the sample size was small, so differences across age, gender, and racial or ethnic diversity were difficult to tease out. Some of the photovoice projects assessed by others in the SFD space have been all female (Hayhurst et al., 2015; Hayhurst, 2017), so cannot distinguish between the experiences of young men versus women. Some of these demographic differences in response to photo voice would be interesting for further study.

\section{CONCLUSION}

The overarching goal of this study was to assess the viability of photovoice as a strategy for giving voice to youth SFD participants. Additionally, there was a focus on finding out how youth-derived data can play a role in the planning process. Centre administrators found great value in the results of the photovoice project. While it has its limitations, photovoice emerged in this study as a viable tool that SFD practitioners and scholars should be using to engage youth in the programme development process, thus empowering the youth well beyond the data they gather. However, we present this as just one example of what can be done to give youth a voice. Finally, it is vital that programme administrators are committed to allowing the youth they serve 
to have a voice in the process, otherwise the exercise is futile. With a willing audience, as was the case here, there is the very real possibility that the SFD programme going forward will be altered by what was learned from the youth of the centre. Not only does this result in empowerment among the youth (seeing their ideas in practice), but also creates a more appropriate and hopefully successful SFD programme overall, that is sure to connect with the youth of the community.

\section{REFERENCES}

Altschuld, J. W., Hsin-Ling, H., \& YiFang, L. (2014). "Needs Assessment and Asset/Capacity Building: A Promising Development in Practice." New Directions for Evaluation, 144, 89-103.

Blevins, M. E. (2017). Exploring Grades 3-8 Principals' Beliefs about the New TNReady Standards: An Assets or Deficits Perspective? Ph.D. dissertation, University of Tennessee.

Burnett, C. (2008). Participatory Action Research in Monitoring and Evaluation of Sport-for-Development Programmes. African Journal for Physical Health Education, Recreation and Dance, 14(3), 225-239.

Burnett, C. (2015). Assessing the Sociology of Sport: On Sport for Development and Peace. International Review for the Sociology of Sport, 50(4-5), 385-390.

Coalter, F. (2007). A Wider Social Role for Sport: Who's Keeping Score? London, UK: Routledge.

Collison, H., \& Marchesseault, D. (2018). Finding the Missing Voices of Sport for Development and Peace (SDP): Using a 'Participatory Social Interaction Research' Methodology and Anthropological Perspectives within African Developing Countries. Sport in Society, 21(2), 226-242.

Costa, S. M., \& Serrano-García, I. (1983). Needs Assessment and Community Development: An Ideological Perspective. Prevention in Human Services, 2(4), 75-88.

Cox, K. (2006). Investigating the Impact of Strength-Based Assessment on Youth with Emotional or Behavioral Disorders. Journal of Child and Family Studies, 15(3), 278-292.

Creswell, J. W., \& Poth, Ch. N. (2017). Qualitative Inquiry and Research Design: Choosing Among Five Approaches. Thousand Oaks, CA: Sage Publications.

Curtis, Ch. A. (2018). Enhancing Global Citizenship through Service Learning: Implications for Capacity Building with Youth. Journal of Community Engagement and Scholarship, 11(1), 38-46.

Darnell, S. C. (2007). Playing with Race: Right to Play and Production of Whiteness in 'Development thorough Sport'. Sport in Society, 10(4), 560-579.

Darnell, S. C. (2012). Sport for Development and Peace: A Critical Sociology. London, UK: Bloomsbury.

Dassah, E., Aldersey, H. M., \& Norman, K. E. (2017). Photovoice and Persons with Physical Disabilities: A Scoping Review of the Literature. Qualitative Health Research, 27(9), 1412-1422.

Delgado, M., \& Humm-Delgado, D. (2013). Asset Assessment and Community Social Work Practice. New York, NY: Oxford University Press.

Dubnewick, M., Hopper, T., Spence, J. C., \& McHugh, T. L. F. (2018). There's a Cultural Pride through our Games: Enhancing the Sport Experiences of Indigenous Youth in Canada through Participation in Traditional Games. Journal of Sport and Social Issues, 42(4), 207-226.

Edwards, M. B. (2015). The Role of Sport in Community Capacity Building: An Examination of Sport for Development Research and Practice. Sport Management Review, 18(1), 6-19.

Giles, A. R., \& Lynch, M. (2012). Postcolonial and Feminist Critiques of Sport for Development. In: Sport for Development, Peace and Social Justice, edited by R. J. Schinke \& S. J. Hanrahan, 89-104. Morgantown, WV: Fitness Information Technology. 
Green, G. P., \& Haines, A. (2015). Asset Building \& Community Development. Thousand Oaks, CA: Sage Publications.

Halsall, T. G., \& Forneris, T. (2016). Behind the Scenes of Youth-Led Community Events: A Participatory Evaluation Approach using Photovoice in a Canadian First Nation Community. Youth Engagement and Health Promotion, 1(2), 1-40.

Hayhurst, L. M. C. (2009). The Power to Shape Policy: Charting Sport for Development and Peace Policy Discourses. International Journal of Sport Policy and Politics, 1(12), 203-227.

Hayhurst, L. M. C. (2017). Image-ining resistance: Using participatory action research and visual methods in sport for development and peace. Third World Thematics: A TWQJournal, 2(1), 117-140.

Hayhurst, L. M. C., Giles, A. R., Radforth, W. M., \& The Vancouver Aboriginal Friendship Centre Society (2015). 'I want to come here to prove them wrong': Using a post-colonial feminist participatory action research (PFPAR) approach to studying sport, gender and development programmes for urban indigenous young women. Sport in Society, 18(8), 952-967.

Hayhurst, L. M. C., Giles, A. R., \& Wright, J. (2016). Biopedagogies and indigenous knowledge: examining sport for development and peace for urban indigenous young women in Canada and Australia. Sport Education and Society, 21(4), 549-569.

Hudson, B. W., Spence, J. C., \& McHugh, T. L. F. (2020). An Exploration of the Physical Activity Experiences of Northern Aboriginal Youth: A Community-Based Participatory Research Project. Qualitative Research in Sport, Exercise and Health, 12(1), 108-124.

Kidd, B. (2008). A New Social Movement: Sport for Development and Peace. Sport in Society, 11(4), 370-380.

Kretzmann, J. P., \& McKnight, J. L. (1993). Building Communities from the Inside Out: A Path toward Finding and Mobilizing a Community's Assets. Chicago, IL: ACTA Publications.

Laureus Sport for Good South Africa (2019). Sport for Development: South Africa Road to Evidence. Cape Town, South Africa: Laureus Sport for Good.

LeCrom, C. W., \& Dwyer, B. (2015). From Evaluator to Insider: An Academic's Guide to Managing Sport for Development Programmes. Sport in Society, 18(6), 652-668.

Lenneis, V., Agergaard, S., \& Evans, A. B. (2020). Women-only Swimming as a Space of Belonging. Qualitative Research in Sport, Exercise and Health AOP, 1-16.

Leung, M. M., Agaronov, A., Entwistle, T., Harry, L., Sharkey-Buckley, J., \& Freudenberg, N. (2017). Voices through Cameras: Using Photovoice to Explore Food Justice Issues with Minority Youth in East Harlem, New York. Health Promotion Practice, 18(2), 211-220.

Levermore, R., \& Beacom, A., eds. (2012). Sport and International Development. New York, NY: Palgrave MacMillan.

Liebenberg, L. (2018). Thinking Critically about Photovoice: Achieving Empowerment and Social Change. International Journal of Qualitative Methods, 17(1), 1-9.

Lindloff, T. R., \& Taylor, B. C. (2011). Qualitative Communication Research Methods (3rd ed.). Thousand Oaks, CA: Sage Publications.

Lyras, A., \& Peachey, J. W. (2011). Integrating Sport-for-Development Theory and Praxis. Sport Management Review, 14(4), 311-326.

Maxwell, J. A. (2013). Qualitative Research Design: An Interactive Approach (3rd ed.). Thousand Oaks, CA: Sage.

McHugh, T. L. F., Holt, N. L., \& Andersen, Ch. (2015). Community-Based Sport Research with Indigenous Youth. New Perspectives in Physical Education Sport and Recreation, 28, 219-224.

Miles, M. B., \& Huberman, A. M. (1994). Qualitative Data Analysis: An Expanded Sourcebook. Thousand Oaks, CA: Sage Publications.

National Center for Children in Poverty (2016). Virginia Demographics of Low-income Children. Retrieved from: http://www.nccp.org/profiles/VA_profile_6.html. 
Nicholls, S., Giles, A. R., \& Sethna, Ch. (2011). Perpetuating the 'Lack of Evidence' Discourse in Sport for Development: Privileged Voices, Unheard Stories and Subjugated Knowledge. International Review for the Sociology of Sport, 46, 249-264.

Novek, S., \& Menec, V. H. (2014). Older Adults' Perceptions of Age-Friendly Communities in Canada: A Photovoice Study. Aging \& Society, 34(6), 1052-1072.

Onwuegbuzie, A. J., \& Collins, K. M. (2007). A Typology of Mixed Methods Sampling Designs in Social Science Research. Qualitative Report, 12(2), 281-316.

Overmars-Marx, T., Thomése, F., \& Moonen, X. (2018). Photovoice in Research Involving People with Intellectual Disabilities: A Guided Photovoice Approach as an Alternative. Journal of Applied Research in Intellectual Disabilities, 31(1), 92-104.

Patton, M. Q. (2002). Two Decades of Developments in Qualitative Inquiry: A Personal, Experiential Perspective. Qualitative Social Work, 1(3), 261-283.

Platt, A. (2016). Sustainable Livelihood Community Level Assessment of Wayanad, Kerala. Master's thesis, Tufts University.

Rowlands, J. (1998). A Word of the Times, but What Does it Mean? Empowerment in the Discourse and Practice of Development. In: Women and Empowerment: Illustrations from the Third World, edited by H. Afshar, 11-34. Hampshire, England: MacMillan Press Ltd.

Schulenkorf, N. (2012). Sustainable Community Development through Sport and Events: A Conceptual Framework for Sport-for-Development Projects. Sport Management Review, 15(1), 1-12.

Spaaij, R., Schulenkorf, N., Jeanes, R., \& Oxford, S. (2018). Participatory Research in Sport-for-Development: Complexities, Experiences and (Missed) Opportunities. Sport Management Review, 21(1), 25-37.

Steward-Withers, R., \& Brook, M. (2009). Sports as a Vehicle for Development: The Influence of Rugby League in/on the Pacific. Development Studies 3, Palmerston North, N. Z.: Massey University. Institute of Development Studies. http://hdl.handle.net/10179/1070.

Strack, R. W., Magill, C., \& McDonagh, K. (2004). Engaging Youth through Photovoice. Health Promotion Practice, 5(1), 49-58.

Svensson, P. G., \& Woods, H. (2017). A Systematic Overview of Sport for Development and Peace Organisations. Journal of Sport for Development, 5(9), 36-48.

Van Manen, S., Avard, G., \& Martinez-Cruz, M. (2015). Co-Ideation of Disaster Preparedness Strategies through a Participatory Design Approach: Challenges and Opportunities Experienced at Turrialba Volcano, Costa Rica. Design Studies, 40, 218-245.

Vlček, P. (2020). A quality framework for assessing the designed curriculum - a basis for the Czech PE curriculum revision. AUC Kinanthropologica, 56(1), 47-55.

Wang, C. C. (2006). Youth Participation in Photovoice as a Strategy for community Change. Journal of Community Practice, 14(1-2), 147-161.

Wang, C. C., \& Burris, M. A. (1997). Photovoice: Concept, Methodology, and Use for Participatory Needs Assessment. Health Education \& Behavior, 24(3), 369-387.

Wang, C. C., Morrel-Samuels, S., \& Hutchinson, P. M. (2004). Flint Photovoice: Community Building among Youths, Adults, and Policymakers. American Journal of Public Health, 94(6), 911-913.

Wang, C. C., \& Pies, Ch. A. (2004). Family, Maternal, and Child Health through Photovoice. Maternal and Child Health Journal, 8(2), 95-102.

Wright, B. A., \& Lopez, S. J. (2002). Widening the Diagnostic Focus: A Case for Including Human Strengths and Environmental Resources. In: Handbook of Positive Psychology, edited by C. R. Synder \& S. J. Lopez, 26-44. New York, NY: Oxford Publications.

Yankeelov, P. A., Faul, A. C., D’Ambrosio, J. G., Collins, W. L., \& Gordon, B. (2015). “Another Day in Paradise": A Photovoice Journey of Rural Older Adults Living with Diabetes. Journal of Applied Gerontology, 34(2), 199-218. 
Zimmerman, E., Haley, A., Walker, A., Woolf, S., Nguyen, K., Shue. W., Kelley, L., Hellman, J., \& Chapman, D. (2016). Health Equity in Richmond, Virginia. Center on Society and Health Report. http://societyhealth.vcu.edu/media/society-health/pdf/RVAHealth EquityFINAL.pdf.

\section{APPENDIX A}

\section{Programme administrators interview guide}

1. Describe your current sport programming.

2. What do you see as the assets and barriers to physical activity and sport participation in the community?

3. What do you see as (general) positive attributes of this community? a. How do you know/how did you draw this conclusion?

4. What are some (general) shortcomings of this community? a. How do you know/how did you draw this conclusion?

5. What is the biggest need in this community?

6. Has your perception of the challenges and assets of the community guided your sport programming? How?

7. After seeing and hearing the perspective of the youth, how (if at all) have your perception of the assets and barriers in the community changed?

8. What was your reaction to seeing (via photovoice photos) what the kids believed to be the challenges and barriers in their community?

9. Discuss the benefits of hearing/seeing the youth's perspective of the challenges and assets in their community.

10. How might you use the youth-identified assets to inform future centre sport programming?

11. How might you use the youth-identified barriers/challenges/ shortcomings to inform future centre sport programming? 